\title{
BMJ Open Examining the reliability and validity of a modified version of the International Physical Activity Questionnaire, long form (IPAQ-LF) in Nigeria: a cross-sectional study
}

\author{
Adewale L Oyeyemi, ${ }^{1}$ Umar M Bello, ${ }^{1}$ Saratu T Philemon, ${ }^{2}$ Habeeb N Aliyu, ${ }^{1}$ \\ Rebecca W Majidadi, ${ }^{1}$ Adetoyeje Y Oyeyemi ${ }^{1}$
}

To cite: Oyeyemi AL, Bello UM, Philemon ST, et al. Examining the reliability and validity of a modified version of the International Physical Activity Questionnaire, long form (IPAQ-LF) in Nigeria: a cross-sectional study. BMJ Open 2014;4: e005820. doi:10.1136/ bmjopen-2014-005820

- Prepublication history for this paper is available online. To view these files please visit the journal online (http://dx.doi.org/10.1136/ bmjopen-2014-005820).

Received 29 May 2014 Revised 7 November 2014 Accepted 10 November 2014

\section{CrossMark}

${ }^{1}$ Department of

Physiotherapy, College of Medical Sciences, University of Maiduguri, Maidugur, Borno, Nigeria

2Department of

Physiotherapy, Jos University Teaching Hospital, Jos, Plateau, Nigeria

Correspondence to Dr Adewale L Oyeyemi; alaoyeyemi@yahoo.com

\section{ABSTRACT}

Objectives: To investigate the reliability and an aspect of validity of a modified version of the long International Physical Activity Questionnaire (Hausa IPAQ-LF) in Nigeria.

Design: Cross-sectional study, examining the reliability and construct validity of the Hausa IPAQ-LF compared with anthropometric and biological variables.

Setting: Metropolitan Maiduguri, the capital city of Borno State in Nigeria.

Participants: 180 Nigerian adults (50\% women) with a mean age of $35.6(S D=10.3)$ years, recruited from neighbourhoods with diverse socioeconomic status and walkability.

Outcome measures: Domains (domestic physical activity (PA), occupational PA, leisure-time PA, active transportation and sitting time) and intensities of PA (vigorous, moderate and walking) were measured with the Hausa IPAQ-LF on two different occasions, 8 days apart. Outcomes for construct validity were measured body mass index (BMI), systolic blood pressure (SBP) and diastolic blood pressure (DBP).

Results: The Hausa IPAQ-LF demonstrated good test-retest reliability (intraclass correlation coefficient, ICC $>75)$ for total PA (ICC $=0.79,95 \% \mathrm{Cl} 0.65$ to 0.82 ), occupational PA (ICC $=0.77,95 \% \mathrm{Cl} 0.68$ to 0.82 ), active transportation (ICC $=0.82,95 \% \mathrm{Cl} 0.75$ to 0.87 ) and vigorous intensity activities (ICC=0.82, $95 \% \mathrm{Cl} 0.76$ to 0.87 ). Reliability was substantially higher for total PA (ICC=0.80), occupational PA (ICC $=0.78)$, leisure-time PA (ICC $=0.75)$ and active transportation $(I C C=0.80)$ in men than in women, but domestic PA (ICC=0.38) and sitting time $(I C C=0.71)$ demonstrated more substantial reliability coefficients in women than in men. For the construct validity, domestic PA was significantly related mainly with SBP $(r=-0.27)$ and DBP $(r=-0.17)$, and leisure-time PA and total PA were significantly related only with SBP $(r=-0.16)$ and BMI $(r=-0.29)$, respectively. Similarly, moderate-intensity PA was mainly related with SBP $(r=-0.16, p<0.05)$ and DBP $(r=-0.21, p<0.01)$, but vigorous-intensity $\mathrm{PA}$ was only related with $\mathrm{BMI}$ $(r=-0.11, p<0.05)$.

\section{Strengths and limitations of this study}

- Systematic adaptation and tailoring of items was performed on the original International Physical Activity Questionnaire long form (IPAQ-LF) to reflect common physical activity (PA) behaviours of adults in Nigeria.

- This is the first study to describe the cultural adaptation and translations of the IPAQ-LF, and to explore its psychometric relevance in an African country.

- Findings establish evidence to support the feasibility of using a modified IPAQ-LF to reliably collect context specific PA behaviours of adults in the African region.

- Exploring construct validity through the relationships of PA with body mass index and resting blood pressure was an important limitation of this study.

- The use of a non-probability sampling technique may limit generalisability of findings to other samples of Nigerian adults with different characteristics from the study's sample.

Conclusions: The modified Hausa IPAQ-LF demonstrated sufficient evidence of test-retest reliability and may be valid for assessing context specific PA behaviours of adults in Nigeria.

\section{INTRODUCTION}

The importance of physical activity (PA) for promoting health and preventing disease is well established. $^{1-3}$ However, for effective health promotion and PA surveillance and monitoring, it is important to have standardised, reliable and valid instruments that can be used to accurately describe population levels and patterns of PA within and across countries. ${ }^{45}$ In this context, the international 
physical activity questionnaire (IPAQ) was developed to obtain internationally comparable data on health-related PA of adults (18-65 years). ${ }^{5} 6$ Two versions of the IPAQ that could be administered by interview or self-completed were developed. The short form (SF) was designed for population surveillance of PA; while the long form (LF) was designed to be appropriate for use in research that requires detailed information on different PA domains, including PA at work, household, during leisure and transportation and time spent in sedentary activities. ${ }^{6}$

The initial evaluation of the IPAQ across 12 countries produced acceptable evidence of reliability and validity that are as good as other self-report measures of PA. ${ }^{5}$ Consequently, in order to enhance the utility of IPAQ and to further evaluate its psychometrics worldwide, efforts have been made to translate and adapt the IPAQ in many other countries, but most of the research in this context were from developed Western countries. ${ }^{7-14}$ In Africa, the psychometric properties of IPAQ have only been tested in South Africa as part of the initial development process of the questionnaire, ${ }^{5}$ and in older adults. ${ }^{15}$ Since the largest increases and burden of non-communicable diseases (NCDs) are in low-income countries where the understanding of evidence-based strategies for increasing PA remains poor, ${ }^{16-19}$ improving PA research is a top priority for them. ${ }^{20}$ However, to advance PA research in Africa, it is important to first develop or tailor standardised measures to be culturally sensitive to PA behaviours of people in the region's countries. Since Nigeria is the most populous country in Africa with culture and languages similar to most of the other West African countries, it is a good choice to evaluate the IPAQ for cultural and psychometric relevance in this country.

Recently, a cultural adaptation study of the IPAQ-SF was conducted among adults in Nigeria, ${ }^{21}$ with good evidence of test-retest reliability similar to findings in some other studies. ${ }^{1022-24}$ However, because the IPAQ-SF is not domain specific and does not provide context-specific information on PA behaviour, it is important to evaluate the IPAQ-LF for relevance in Nigeria. Psychometric evaluation of a culturally modified version of the IPAQ-LF in sub-Saharan African countries can impact PA research and surveillance in the African region where the prevalence of inactivity related NCDs is on the increase. ${ }^{20} 25$ The aim of the present study was to investigate the reliability and an aspect of validity of a modified version of the IPAQ-LF among adults in Nigeria.

\section{METHODS}

\section{Participants}

A purposive sample of 180 adults from eight neighbourhoods that varied in socioeconomic status and walkability in Maiduguri city were recruited for the study. The sampling and neighbourhood selection strategy have been described in detail elsewhere. ${ }^{26}$ Maiduguri, with an estimated population of 749123 people, is the capital and largest city of Borno State in North-Eastern Nigeria. ${ }^{27}$
The city attracts immigrants from neighbouring countries of Cameroon, Niger and Chad Republic and the Hausa language is the common means of communication for commercial activities among the diverse inhabitants of Maiduguri. ${ }^{27}{ }^{28}$ Participants were eligible for this study if they were willing to self-complete a written survey twice in either Hausa or English language. However, researchers (UMB and STP) were in attendance to provide translation and interpretation assistance to participants $(n=11)$ who required help to complete the survey. Additional eligibility criteria included living within the identified neighbourhood categories in the past 12 months, being adults (18-65 years) and not having any disability that prevented independent walking. All participants were fully informed of the study protocol and provided signed informed consent. The study protocol was approved by the Research and Ethics Committee of the University of Maiduguri Teaching Hospital, Maiduguri, Nigeria. Data were collected between March and May, 2012.

\section{Measures}

The adapted IPAQ—-long Hausa version

The cultural adaptation, translation and back translation of the Hausa version of IPAQ-LF is similar to that of the Hausa IPAQ-SF that has been described in detail elsewhere. ${ }^{21}$ Briefly, interviews were conducted with public health experts, exercise scientists and local people, not highly educated, to identify the items and examples of PA on the original questionnaire that needed to be culturally adapted. Several cultural adaptations were made to the original items to reflect the reality in Nigeria. First, adjustments to English words such as 'vigorous' and 'moderate' activity, which can be misunderstood and not associated with PA behaviours in Nigeria, were replaced with words that are more representative of the language used in Nigeria, such as 'very hard' and 'hard', respectively. Second, examples of various intensities of activity that are common in the Nigerian culture were added, and those already on the questionnaire but not common in the Nigerian context were replaced with culturally applicable examples that are equivalent in energy intensity (metabolic energy turnovers, METs) with the original items and examples. Third, concepts such as PA and walking for transportation, which were misconstrued outside the health context, were refined to indicate they were referring to health behaviours.

After adaptation, the questionnaire was independently translated from English into Hausa by two native speakers of Hausa who also speak English, and who are able to read and write in both languages. One of the translators was familiar with the questionnaire and the second was an expert in Hausa. The translated questionnaires were mutually revised by the translators and the research team for consistency and then back translated into English by a third bilingual person who was familiar with the construct measured by IPAQ. The back translated version was checked by the research team for any discrepancies and to ensure that the construct measures by 
IPAQ had not been lost during the adaptation and translation process.

The modified questionnaire (available in Hausa and also English), hereafter referred to as the Hausa version of the long international physical activity questionnaire (Hausa IPAQ-LF), contains 31 questions that ask about PA in the past 7 days in terms of frequency (days/week) and duration (minutes/day) spent in four activity domains (transportation, occupation, domestic and leisure time), and included sections on walking, moderate-intensity and vigorous-intensity activities, and time spent in sedentary behaviour (sitting during leisure and motorised transportation). The Hausa IPAQ-LF data were presented as the MET-minute/week for total walking, moderate and vigorous intensity activity and overall PA across the four domains, and in each of the domains. The MET intensity values used to score the Hausa IPAQ-LF questions in this study were 8 METs for vigorous activity, 4 METs for moderate activity and 3.3 METs for walking. ${ }^{2}{ }^{6}$ One MET represents the energy expended while sitting quietly at rest and is equivalent to $3.5 \mathrm{~mL} / \mathrm{kg} / \mathrm{min}$ of $\mathrm{VO}_{2}$ Max. ${ }^{3}$ To assess the test-retest reliability of the Hausa IPAQ-LF, participants selfcompleted all items on the measure twice, with an interval of 1 week between administrations.

\section{Anthropometrical and biological measurements}

Body weight (to nearest $0.5 \mathrm{~kg}$ ) and height (to nearest $0.1 \mathrm{~cm}$ ) were measured in light clothing using a digital scale and stadiometer. Body mass index (BMI) was calculated as body weight divided by the square of height $\left(\mathrm{kg} / \mathrm{m}^{2}\right)$. The principal cut-off points as recommended by WHO were used to create the categories: underweight $\left(<18.5 \mathrm{~kg} / \mathrm{m}^{2}\right)$, normal weight $\left(18.5-<25 \mathrm{~kg} / \mathrm{m}^{2}\right)$, overweight $\left(25-<30 \mathrm{~kg} / \mathrm{m}^{2}\right)$ and obese $\left(\geq 30 \mathrm{~kg} / \mathrm{m}^{2}\right){ }^{29}$ Resting blood pressure and heart rate were measured with a Digital Sphygmomanometer (Diagnostic Advanced Wrist Blood Pressure Monitor, Model 6016, USA). BMI and resting diastolic blood pressure (DBP) have previously been used for validating the IPAQ. ${ }^{724}$ Similarly, for this study, construct validity was evaluated by investigating the relationship of outcomes from the Hausa IPAQ-LF with anthropometric (BMI) and biological (SBP and DBP) measurements, and also in part by comparing the differences in time spent in PA and sitting, across sociodemographic subgroups. These types of validation for PA measures have been referred as indirect or construct validity in previous studies. ${ }^{7} 2430$

\section{Sociodemographic characteristics}

Information on age, gender, marital status, religion, income, educational level and employment status were elicited from the participants. Marital status was classified as married or not married. Educational level was classified as more than secondary school education, secondary school education and less than secondary school education. Employment status was classified into white collar (government or private employed), blue collar (self-employed, trader, artisan, etc) and unemployed (homemaker, student, retired or unable to find job).

\section{Data analysis}

Descriptive data were reported as mean, SD and percentages. Mean group differences for continuous variables by gender were examined by independent $\mathrm{t}$ test, and for dichotomous variables by $\chi^{2}$ statistics. The reliability analyses were performed using two strategies. First, the two-way mixed model (single measure) intraclass correlation coefficient (ICC) with 95\% CI between the continuous scores obtained on first and second administration of the Hausa IPAQ-LF was calculated. The ICCs were calculated overall, and by gender and socioeconomic status. ICC estimates $>0.75$ were considered as good reliability scores, between 0.50 and 0.75 as moderate reliability, and $<0.50$ as poor reliability. ${ }^{31}$ Second, the Bland and Altman Method was used to assess agreement on scores of PA from the first and second administrations. ${ }^{32}$ Variables used for the Bland and Altman analysis were weekly time spent in moderate-to-vigorous activity (MVPA), total PA and sitting. MVPA was computed by summing the total $\mathrm{min} /$ week of reported PA of moderate and vigorous intensities across all four domains. For total PA, the total $\mathrm{min} /$ week of activities in each domain was summed (total work+total transport+total domestic+total leisuretime min/week scores) to gain an overall estimate of PA in a week. Also, the independent $t$ test and one-way ANOVA were used as appropriate to compare the time spent (min/week) in PA at both administrations across sociodemographic subgroups. To assess construct validity, the non-parametric Spearman correlation coefficients ( $r$ ) were utilised to explore the relationship between MET-min/week of PA from the Hausa IPAQ-LF, and resting blood pressure and BMI. Data were analysed using Statistical Package for the Social Sciences (SPSS), V.15.0 for Windows (SPSS Inc, Chicago, Illinois, USA) and the level of significance was set at $\mathrm{p}<0.05$.

\section{RESULTS}

The sociodemographic characteristic of the participants are shown in table 1 . The participants comprised equally of women and men, with a mean age of $35.6 \pm 10.3$ years and BMI of $23.8 \pm 3.9 \mathrm{~kg} / \mathrm{m}^{2}$. The majority of the participants were married $(58.9 \%, \mathrm{n}=106)$, had more than secondary school education $(62.7 \%, \mathrm{n}=111)$ and were employed $(75 \%, \mathrm{n}=117)$. Compared to men, the women were more likely to be married $(71.1 \%$ vs $46.7 \%$, $\mathrm{p}=0.001)$ and unemployed $(52.2 \%$ vs $17.8 \%, \mathrm{p}<0.001)$, but men were more likely to have more than secondary school education $(76.7 \%$ vs $48.2 \%$, $\mathrm{p}<0.001)$.

\section{Reliability}

Table 2 shows the test-retest reliability of the modified IPAQ-LF. Overall, reliability coefficients were good (ICC >75) for total PA, occupational PA, active transportation 
Table 1 Descriptive characteristics of the participants $(\mathrm{N}=180)$

\begin{tabular}{|c|c|c|c|}
\hline Variables & Total sample $(\mathrm{N}=180)$ & Men $(n=90,50 \%)$ & Women $(n=90,50 \%)$ \\
\hline \multicolumn{4}{|l|}{ Age (years) } \\
\hline Mean $( \pm S D)$ & $35.6 \pm 10.3$ & $35.7 \pm 8.3$ & $35.5 \pm 11.9$ \\
\hline \multicolumn{4}{|l|}{ Marital status $(n, \%)^{*}$} \\
\hline Not married & $74(41.1)$ & $48(53.3)$ & $26(28.9)$ \\
\hline Married & $106(58.9)$ & $42(46.7)$ & $64(71.1)$ \\
\hline \multicolumn{4}{|l|}{ BMI $\left(\mathrm{kg} / \mathrm{m}^{2}\right)$} \\
\hline Mean $( \pm S D)$ & $23.8 \pm 3.9$ & $23.8 \pm 3.5$ & $23.8 \pm 4.4$ \\
\hline \multicolumn{4}{|l|}{ BMI category (n, \%) } \\
\hline Underweight & $14(7.8)$ & $4(4.4)$ & $10(11.1)$ \\
\hline Normal weight & $107(59.4)$ & $58(64.4)$ & $49(54.4)$ \\
\hline Overweight/obese & 59 (32.8) & $28(31.2)$ & $31(34.5)$ \\
\hline \multicolumn{4}{|l|}{ Ethnicity $(n, \%)$} \\
\hline Hausa/Fulani & $21(11.7)$ & $10.1(11.1)$ & $11(12.2)$ \\
\hline Igbo & $8(4.4)$ & $5(5.6)$ & $3(3.3)$ \\
\hline Yoruba & $10(5.6)$ & $6(6.7)$ & $4(4.4)$ \\
\hline Kanuri/Shuwa Arab & $44(24.4)$ & $23(25.6)$ & $21(23.3)$ \\
\hline Others & 97 (53.9) & $46(51.1)$ & $51(56.7)$ \\
\hline \multicolumn{4}{|l|}{ Educational level (n, \%)* } \\
\hline >Secondary school & $111(62.7)$ & $11(12.2)$ & $17(19.5)$ \\
\hline Secondary & $38(21.5)$ & $10(11.1)$ & $28(32.5)$ \\
\hline <Secondary school & $28(15.8)$ & $69(76.7)$ & $42(48.2)$ \\
\hline \multicolumn{4}{|c|}{ Occupational status $(n, \%)^{*}$} \\
\hline Unemployed & $63(35)$ & $16(17.8)$ & $47(52.2)$ \\
\hline Blue collar & $45(25)$ & $28(31.1)$ & $17(18.9)$ \\
\hline White collar & $72(40)$ & $46(51.1)$ & $26(28.9)$ \\
\hline
\end{tabular}

${ }^{*}$ Significant difference between samples $(p<0.05)$.

BMI, body mass index.

and vigorous intensity (very hard) PA. Domestic PA, sitting activity and leisure PA demonstrated moderate reliability (ICC ranges from 0.51 to 0.71 ). While the reliability coefficients of total PA (ICC $=0.80,95 \%$ CI 0.69 to 0.87 ), active transportation (ICC $=0.83,95 \%$ CI 0.73 to 0.89 ), occupational PA (ICC $=0.78,95 \%$ CI 0.66 to 0.85 ) and leisure time PA ( $\mathrm{ICC}=0.75,95 \%$ CI 0.63 to 0.84 ) were substantially higher among men than women, reliability coefficients for domestic PA (ICC $=0.38,95 \%$, CI 0.01 to 0.57 ) and sitting time (ICC $=0.71,95 \%$ CI 0.46 to
$0.85)$ were higher among women than men. According to the intensity of PA, ICCs range between 0.61 and 0.82 , with the lowest value recorded for moderate intensity (hard) PA and the highest value for vigorous intensity (very hard) PA. The reliability coefficients for walking, moderate-intensity (hard) and vigorous intensity (very hard) activities were substantially greater in men than in women.

Similarly, socioeconomic status differences were observed in the reliability coefficients of the modified

Table 2 Test-reliability based on intraclass correlation coefficient for Hausa IPAQ-LF, overall and by gender

\begin{tabular}{|c|c|c|c|c|}
\hline Total $(\mathrm{N}=180$ & & & & \\
\hline $\begin{array}{l}\text { Test } 1 \\
\text { (mean (SD)) }\end{array}$ & $\begin{array}{l}\text { Test } 2 \\
\text { (mean (SD)) }\end{array}$ & ICC (95\% Cl) & $\begin{array}{l}\text { Women }(n=90) \\
\text { ICC }(95 \% \mathrm{Cl})\end{array}$ & $\begin{array}{l}\text { Men }(n=90) \\
\text { ICC }(95 \% \mathrm{Cl})\end{array}$ \\
\hline
\end{tabular}

\begin{tabular}{lccccc}
\hline PA Measure (MET×min/week) & & & & \\
Total PA, all domain & $2160.6(2691.1)$ & $1612.8(1612.8)$ & $0.76(0.65$ to 0.82$)$ & $0.45(0.08$ to 0.67$)$ & $0.80(0.69$ to 0.87$)$ \\
Occupation & $619.1(1671.5)$ & $497.5(1332.9)$ & $0.77(0.68$ to 082$)$ & $0.64(0.46$ to 0.77$)$ & $0.78(0.66$ to 0.85$)$ \\
Active transport & $468.1(684.7)$ & $440.5(605.7)$ & $0.82(0.75$ to 0.87$)$ & $0.63(0.40$ to 0.77$)$ & $0.83(0.73$ to 0.89$)$ \\
Domestic & $597.6(754.6)$ & $473.4(673.7)$ & $0.50(0.32$ to 0.62$)$ & $0.38(0.01$ to 0.57$)$ & $0.33(-0.01$ to 0.56$)$ \\
Leisure & $377.0(1096.3)$ & $196.7(920.2)$ & $0.71(0.60$ to 0.78$)$ & $0.69(0.53$ to 0.79$)$ & $0.75(0.63$ to 0.84$)$ \\
Sitting & $2263.0(715.8)$ & $2235.4(818.9)$ & $0.62(0.42$ to 0.75$)$ & $0.71(0.46$ to 0.85$)$ & $0.48(0.06$ to 0.72$)$ \\
PA by intensity (METxmin/week) & $613.6(635.6)$ & $534.6(449.1)$ & $0.63(0.48$ to 0.74$)$ & $0.57(0.29$ to 0.74$)$ & $0.65(0.44$ to 0.78$)$ \\
Walking & $986.9(1365.9)$ & $716.1(1164.6)$ & $0.61(0.46$ to 0.71$)$ & $0.42(0.11$ to 0.62$)$ & $0.67(0.49$ to 0.78$)$ \\
Moderate & $526.5(1543.7)$ & $394.1(1431.1)$ & $0.82(0.76$ to 0.87$)$ & $0.55(0.30$ to 0.71$)$ & $0.86(0.78$ to 0.91$)$ \\
\hline
\end{tabular}


IPAQ-LF (table 3). Across all domains of PA, reliability coefficients were substantially higher among participants with less than secondary school education (ICC from 0.77 (sitting activity) to 0.92 (leisure activity)) compared to those with secondary school education (ICG from 0.28 (active transport) to 0.58 (occupational activity)) and those with higher than secondary school education (ICC from 0.23 (sitting activity) to 0.67 (active transport)). While reliability coefficients were higher for overall PA (ICC $=0.80,95 \%$ CI 0.71 to 0.86 ), active transport (ICC $=0.83,95 \%$ CI 0.74 to 0.88 ), occupational PA (ICC $=0.79,95 \%$ CI 0.70 to 0.86 ) and leisure-time PA (ICC $=0.79$, 95\% CI 0.69 to 0.85 ) among participants who were employed compared to their unemployed counterparts, it was higher for domestic PA (ICC $=0.65$, $95 \%$ CI 0.43 to 0.79 ) and sitting time (ICC $=0.68,95 \%$ CI 0.36 to 0.83 ) among participants who were unemployed than in the employed subgroup.

Figures 1-3 (Bland-Altman plots) illustrate the agreement in the scores (min/week) of total PA, MVPA and sitting between the first and second administrations of Hausa IPAQ-LF. For total PA, the mean difference was $106.7 \mathrm{~min} /$ week, with wide $95 \%$ limits of agreement (-762.2 to $965.6 \mathrm{~min} /$ week). For MVPA, the mean difference was about one and half hours per week (91.6 min/week), and also demonstrating wide $95 \%$ limits of agreement ( -744.5 to $927.7 \mathrm{~min} /$ week). For sitting time, the mean difference was small $(26 \mathrm{~min} /$ week) and the $95 \%$ limits of agreement ranged from -2178.1 to $2230.9 \mathrm{~min} /$ week.

Table 4 shows the patterns of PA across sociodemographic subgroups during the first (IPAQ1) and second (IPAQ2) administrations of the modified IPAQ-LF. Overall and across all stratified variables, time spent in PA reported during the first administration tends to be higher than that reported during the second administration. At both time points, men reported significantly $(\mathrm{p}<0.05)$ higher mean time $(\mathrm{min} /$ week $)$ in active transportation, occupational PA and leisure-time PA than women. However, women spent significantly $(p<0.001)$ more time $(\mathrm{min} /$ week) in domestic PA than men (IPAQ1=236.9 vs 82.3, IPAQ2=195.5 vs 52.4). For educational status, participants who had lower than secondary school education compared to those with at least secondary school education reported statistically significant higher mean time (min/week) at both time points for total PA, active transport, occupational PA, walking and vigorous intensity activity compared to those with at least secondary school education. While participants who were employed reported statistically significant $(p<0.05)$ greater time $(\mathrm{min} /$ week) in total PA $(\mathrm{IPAQ} 1=441.1$ vs 285.1, IPAQ2 $=359.4$ vs 141.0), active transportation (IPAQ1 $=43.8$ vs 21.1 , IPAQ2=36.9 vs 18.3 ) and work PA (IPAQ1=195.5 vs 41.8, IPAQ2=164.1 vs 40.1) than those who were unemployed, the unemployed reported statistically significant $(\mathrm{p}<0.05)$ higher time in domestic activity $\quad(\mathrm{IPAQ} 1=210.6$ vs 132.1 , IPAQ2=205.0 vs 112.6) compared to the employed.

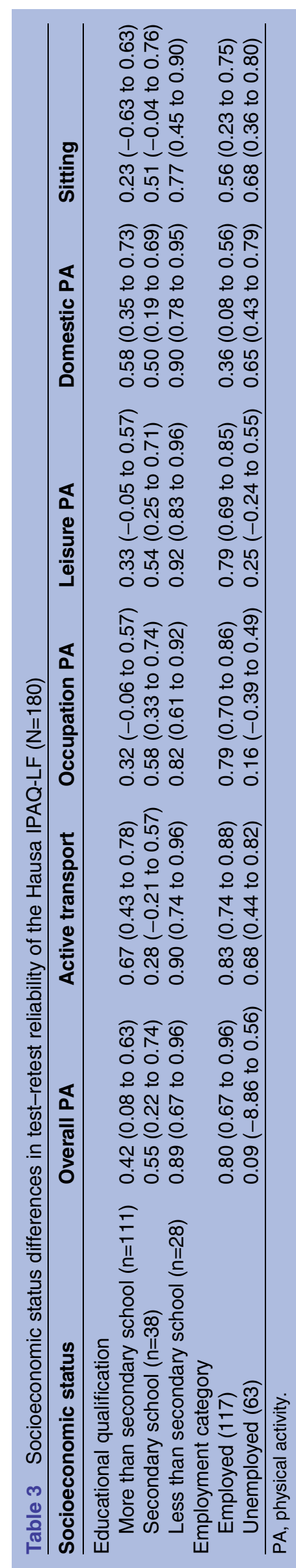




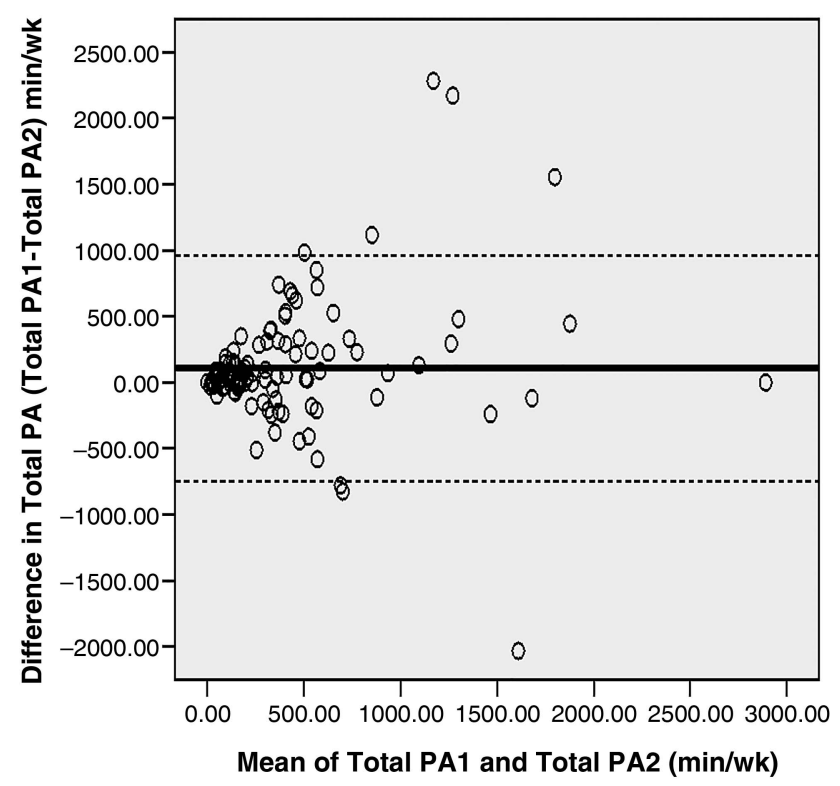

Figure 1 Bland-Altman plot min/week reported in total physical activity (PA) for the first and second administrations of Hausa IPAQ-LF. Mean difference: $106.7 \pm 2 \mathrm{SD}=-762.2$ to 965.6.

\section{Construct validity}

Overall, correlations between energy expenditure (MET-min/week) according to the modified IPAQ-LF and anthropometric and biological measures were statistically significant in the expected direction for all domains and intensities of PA, except for occupation and active transport domains, and walking (table 5). In the full sample, domestic PA was mainly related with SBP $(\mathrm{r}=-0.27, \mathrm{p}<0.01)$ and DBP $(\mathrm{r}=-0.17, \mathrm{p}<0.05)$, while leisure $\mathrm{PA}$ and total $\mathrm{PA}$ were only related with $\mathrm{SBP}$

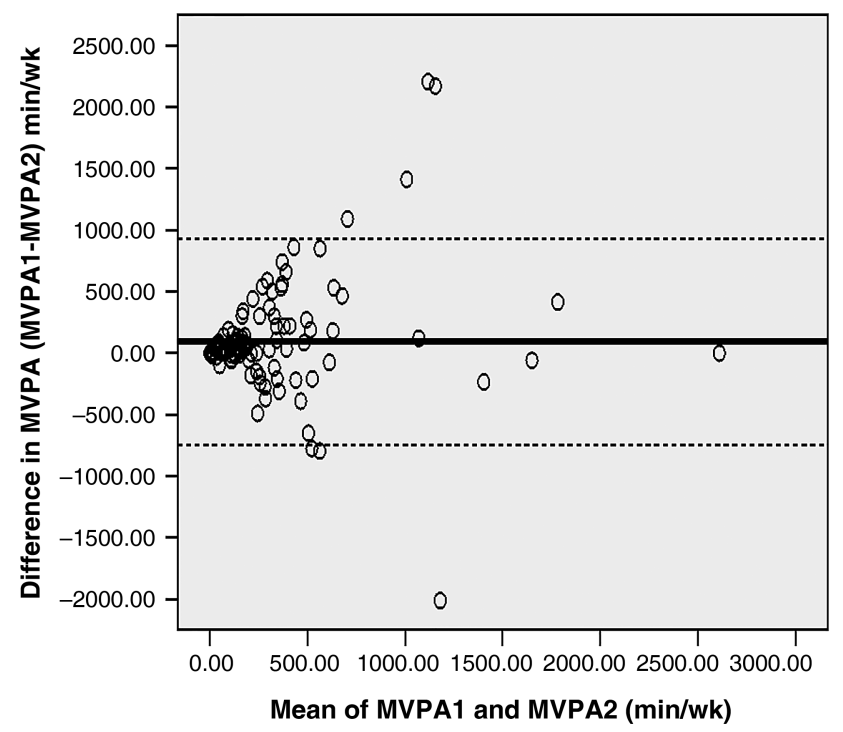

Figure 2 Bland-Altman plot min/week reported in moderate-to-vigorous physical activity (MVPA) for the first and second administrations of Hausa IPAQ-LF. Mean difference: $91.6 \pm 2 \mathrm{SD}=-744.5$ to 927 .

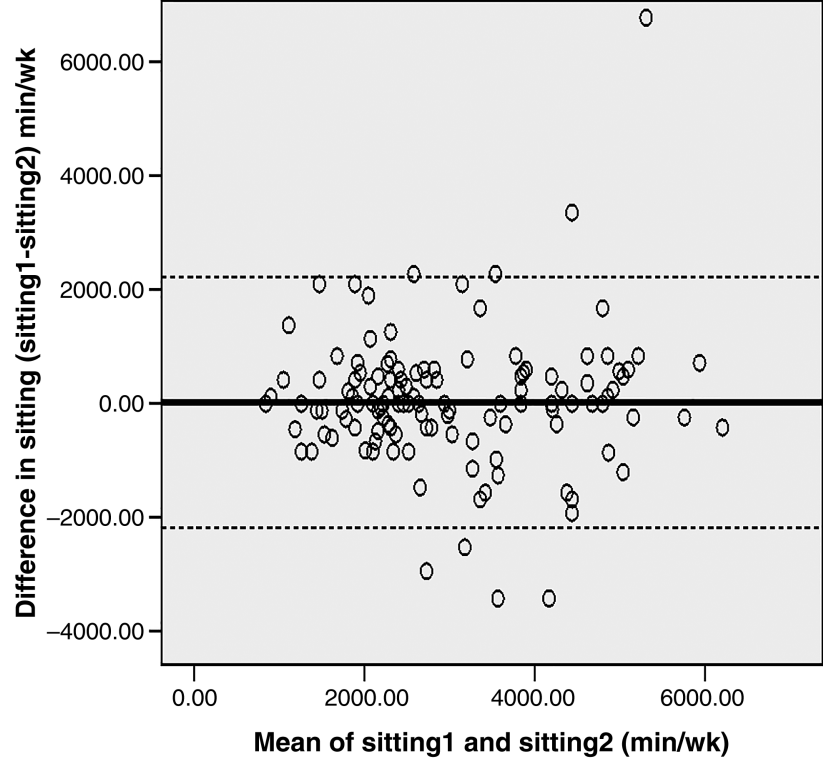

Figure 3 Bland-Altman plot min/week reported in sitting for the first and second administrations of Hausa IPAQ-LF. Mean difference: $26.4= \pm 2 S D=-2178.1$ to 2230.9 .

$(\mathrm{r}=-0.16, \mathrm{p}<0.05)$ and BMI $(\mathrm{r}=-0.29, \mathrm{p}<0.01)$, respectively. Similarly, moderate-intensity PA was mainly related with SBP $(\mathrm{r}=-0.16, \mathrm{p}<0.05)$ and DBP $(\mathrm{r}=-0.21, \mathrm{p}<0.01)$, but vigorous-intensity $\mathrm{PA}$ was only related with BMI $(\mathrm{r}=-0.11, \mathrm{p}<0.05)$. In the gender-based analyses, total PA, domestic PA and sedentary time were more consistently related with anthropometric and biological variables. The strongest $r$ value $(-0.41)$ was found for the relationship between total PA and BMI for the male subgroup. The $r$ value of -0.23 was reached between total PA and DBP for the women subgroup. Only in women was domestic PA significantly related with BMI $(r=-0.23)$, DBP $(r=-0.20)$ and SBP $(r=-0.31)$. Leisure-time PA $(\mathrm{r}=-0.39)$ and occupational PA $(\mathrm{r}=-0.22)$ were significantly related with BMI only in men. The rho value for the relationship between sitting time and BMI was slightly higher in women $(r=0.19)$ than in men $(\mathrm{r}=0.15)$.

\section{DISCUSSION}

This study examined the reliability and an aspect of validity of a modified version of the IPAQ-LF in Nigeria. The findings generally indicated acceptable test-retest reliability and modest construct validity for items of the modified IPAQ-LF among Nigerian adults. To the best of our knowledge, the present study is the only one to examine the reliability and validity of the long version of IPAQ that has been modified specifically to an indigenous African culture and language.

We found evidence for good reliability with high correlations between the test-retest for total PA, occupational PA, active transportation and vigorous intensity activity. Our results show that except for domestic PA 
Table 4 Differences in time spent in physical activity overall, and by gender and socioeconomic status subgroups

\begin{tabular}{|c|c|c|c|c|c|c|c|c|}
\hline & \multirow[b]{2}{*}{$\begin{array}{l}\text { Total } \\
\text { Mean } \pm S D\end{array}$} & \multicolumn{2}{|l|}{ Gender } & \multicolumn{3}{|l|}{ Education } & \multicolumn{2}{|l|}{ Employment } \\
\hline & & $\begin{array}{l}\text { Men } \\
\text { Mean } \pm \text { SD }\end{array}$ & $\begin{array}{l}\text { Women } \\
\text { Mean } \pm \text { SD }\end{array}$ & $\begin{array}{l}\text { >Secondary } \\
\text { Mean } \pm \text { SD }\end{array}$ & $\begin{array}{l}\text { Secondary } \\
\text { Mean } \pm S D\end{array}$ & $\begin{array}{l}\text { <Secondary } \\
\text { Mean } \pm \text { SD }\end{array}$ & $\begin{array}{l}\text { Employed } \\
\text { Mean } \pm \text { SD }\end{array}$ & $\begin{array}{l}\text { Unemployed } \\
\text { Mean } \pm \text { SD }\end{array}$ \\
\hline \multicolumn{9}{|c|}{$P A$ by domain (min/week) } \\
\hline \multicolumn{9}{|c|}{ Total PA, all domain } \\
\hline IPAQ1 & $405.2(507.8)$ & 460.7 (582.9) & $326.8(367.8)$ & $334.0(400.8)$ & $384.8(514.8)$ & $849.2(764.1)^{\star *}$ & $441.1(530.2)$ & $285.1(408.6)^{*}$ \\
\hline IPAQ2 & $308.4(440.3)$ & $319.7(522.8)$ & $291.9(282.9)$ & $285.1(295.1)$ & $184.8(264.4)$ & $803.0(929.6)^{\star \star}$ & $359.4(481.6)$ & $141.0(185.2)^{\star}$ \\
\hline \multicolumn{9}{|c|}{ Active transport } \\
\hline IPAQ1 & $35.8(89.7)$ & $52.4(127.7)$ & $19.5(17.7)^{\star}$ & $28.3(47.7)$ & $28.9(45.02)$ & $76.4(198.7)^{*}$ & $43.8(109.4)$ & $21.1(21.9)^{\star}$ \\
\hline IPAQ2 & $30.4(76.7)$ & $41.2(106.3)$ & $19.3(17.5)^{*}$ & $23.6(30.6)$ & $20.3(30.9)$ & $74.3(182.6)^{*}$ & $36.9(94.1)$ & $18.3(14.7)^{\star}$ \\
\hline \multicolumn{9}{|l|}{ Work } \\
\hline IPAQ1 & $160.1(380.8)$ & $217.5(466.8)$ & $79.1(179.9)^{*}$ & $114.8(291.0)$ & $122.9(365.6)$ & $546.7(615.7)^{\star *}$ & $195.5(418.8)$ & $41.8(162.2)^{*}$ \\
\hline IPAQ2 & $135.3(310.3)$ & $172.5(372.8)$ & $80.6(171.9)^{\star}$ & $104.1(232.2)$ & $160.9(196.1)$ & $531.6(595.8)^{\star \star}$ & $164.1(341.7)$ & $40.1(133.0)^{*}$ \\
\hline \multicolumn{9}{|l|}{ Domestic } \\
\hline IPAQ1 & $159.6(202.2)$ & $82.3(120.6)$ & $236.9(235.8)^{\star \star}$ & $141.2(182.4)$ & $173.3(238.5)$ & $165.4(159.4)$ & $132.1(170.7)$ & $210.6(243.8)^{\star}$ \\
\hline IPAQ2 & 123.9 (163.9) & $52.4(74.9)$ & $195.5(190.1)^{\star \star}$ & $131.9(182.5)$ & $107.6(130.4)$ & $147.3(189.1)$ & 112.6 (163.9) & $205.0(163.3)^{\star}$ \\
\hline \multicolumn{9}{|l|}{ Leisure } \\
\hline IPAQ1 & $62.4(159.1)$ & $75.0(211.1)$ & $10.5(27.3)^{\star \star}$ & $47.0(97.3)$ & $92.7(209.4)$ & $38.2(160.1)$ & $69.7(157.6)$ & $48.7(162.3)$ \\
\hline IPAQ2 & 30.5 (118.2) & $50.6(160.7)$ & $10.1(38.5)^{\star \star}$ & $23.4(51.4)$ & $24.7(91.4)$ & $71.5(256.5)$ & $43.1(143.5)$ & $17.0(28.7)^{\star}$ \\
\hline \multicolumn{9}{|l|}{ Sitting } \\
\hline IPAQ1 & $2263.0(715.8)$ & $2188.8(759.7)$ & $2330.7(674.8)$ & $2280.0(618.7)$ & $2433.9(693.7)$ & $2180.9(760.8)$ & $2159.4(775.9)$ & $2337.6(667.2)$ \\
\hline IPAQ2 & 2235.4 (819.9) & 2208.7 (916.9) & $2259.6(728.1)$ & $2420.7(638.7)$ & $2215.3(663.1)$ & $2160.0(1111.4)$ & $2170.6(870.5)$ & $2282.0(785.5)$ \\
\hline \multicolumn{9}{|c|}{$P A$ by intensity (min/week) } \\
\hline \multicolumn{9}{|c|}{ Walking } \\
\hline IPAQ1 & $178.5(221.5)$ & $241.1(271.9)$ & $128.2(100.8)^{*}$ & $194.4(268.1)$ & $133.4(85.6)$ & $266.9(285.4)^{\star}$ & $192.0(245.7)$ & $133.3(96.2)^{\star}$ \\
\hline IPAQ2 & $142.5(141.8)$ & 148.5 (137.9) & 133.7 (147.9) & $151.7(138.4)$ & $103.6(94.7)$ & $200.3(209.1)^{\star}$ & $150.7(146.6)$ & $115.4(122.7)$ \\
\hline \multicolumn{9}{|l|}{ Moderate } \\
\hline IPAQ1 & 201.9 (326.9) & $193.0(214.5)$ & $214.5(247.8)$ & $187.3(266.5)$ & 194.9 (386.5) & 309.7 (381.7) & $221.2(347.4)$ & 137.7 (239.9) \\
\hline IPAQ2 & $133.9(238.5)$ & 114.2 (276.9) & $162.7(165.6)$ & $132.9(177.8)$ & 88.0 (197.2) & $319.0(482.1)^{\star}$ & 153.9 (266.2) & $68.0(76.4)^{\star}$ \\
\hline \multicolumn{9}{|l|}{ Vigorous } \\
\hline IPAQ1 & 94.1 (211.8) & $123.7(249.6)$ & $52.2(133.2)^{*}$ & 32.9 (81.9) & 129.5 (208.2) & $268.0(459.7)^{\star \star}$ & $90.2(214.6)$ & $127.1(204.6)$ \\
\hline IPAQ2 & 78.4 (206.9) & $86.8(227.4)$ & $46.2(73.4)$ & $52.2(140.2)$ & $55.2(127.0)$ & $292.8(461.5)^{\star \star}$ & 92.8 (226.9) & $130.9(107.8)$ \\
\hline
\end{tabular}


Table 5 Construct validity of Hausa IPAQ-LF: Spearman correlations between energy expenditure (METxmin/week) from Hausa IPAQ-LF, and anthropometric and biological variables $(\mathrm{N}=180)$

\begin{tabular}{|c|c|c|c|c|c|c|c|c|c|}
\hline \multirow[b]{2}{*}{ MET×min/week } & \multicolumn{3}{|c|}{ Overall $(\mathrm{N}=180)$} & \multicolumn{3}{|c|}{ Female $(n=90)$} & \multicolumn{3}{|c|}{ Male $(n=90)$} \\
\hline & $\overline{\mathrm{BMI}}$ & DBP & SBP & BMI & DBP & SBP & BMI & DBP & SBP \\
\hline \multicolumn{10}{|l|}{ PA domains } \\
\hline Total PA & $-0.29^{\star \star}$ & $-0.17^{\star}$ & -0.09 & -0.09 & $-0.23^{\star \star}$ & -0.04 & $-0.41^{* *}$ & -0.08 & -0.14 \\
\hline Occupation PA & -0.12 & -0.09 & 0.01 & 0.02 & 0.02 & -0.05 & $-0.22^{\star *}$ & -0.17 & -0.08 \\
\hline Active transport PA & -0.05 & -0.04 & -0.01 & -0.10 & -0.13 & -0.02 & -0.04 & -0.02 & -0.80 \\
\hline Domestic PA & -0.07 & $-0.17^{\star}$ & $-0.26^{\star \star}$ & $-0.23^{\star *}$ & $-0.20^{*}$ & $-0.31^{* *}$ & 0.04 & -0.14 & -0.04 \\
\hline Leisure PA & 0.09 & -0.08 & $-0.16^{\star}$ & -0.11 & 0.02 & 0.08 & $-0.39^{* *}$ & -0.12 & -0.06 \\
\hline Sitting & 0.16 & -0.09 & 0.04 & 0.19 & 0.12 & 0.05 & 0.15 & -0.09 & 0.05 \\
\hline \multicolumn{10}{|l|}{ PA intensity } \\
\hline Walking & 0 & -0.09 & -0.03 & 0.19 & -0.05 & 0.08 & -0.05 & -0.11 & -0.15 \\
\hline Moderate & -0.02 & $0.21^{*}$ & $0.16^{\star}$ & 0.02 & -0.14 & -0.08 & 0.02 & $-0.25^{\star *}$ & -0.16 \\
\hline Vigorous & $-0.11^{*}$ & -0.06 & 0.03 & -0.16 & 0.01 & 0.02 & $-0.13 \dagger$ & -0.12 & -0.11 \\
\hline
\end{tabular}

${ }^{*} p<0.05 ;{ }^{* *} p<0.01$.

BMI, body mass index; DBP, diastolic blood pressure; MET, metabolic energy turnover; PA, physical activity; SBP, systolic blood pressure.

and sitting time, ICC values for domains of PA were consistently above 0.70 , a level of reproducibility that has been considered acceptably good for IPAQ data. ${ }^{33} 34$ Similar to a previous IPAQ-LF study in Hong Kong, ${ }^{34}$ domestic activity demonstrated the lowest ICC value in our study. However, it is possible that the infrequent nature of household activities undertaken, especially by men, may account for the low reliability reported for domestic PA in our study. In addition to the traditional African patriarchal norm that makes most African men rarely engage in indoor household activities, men in the high socioeconomic group in Nigeria may also not engage in outdoor domestic activities such as gardening and outdoor home appliances and equipment maintenance, because they are able to employ the services of domestic helpers and repair men. Our findings of lower reliability for domestic activity among men, those with more than secondary school education and those who were employed compared to their counterparts seem to support this assumption.

The highest and strongest reliability coefficients $(0.82)$ were found for active transportation as well as vigorous intensity activity. Perhaps active transportation was more stable, consistent and reproducible over time than other PA domains because it is a common and ubiquitous PA behaviour in the African region. Mostly, the performance of active transportation, especially walking, is often out of necessity rather than choice within the African context. Our finding of higher ICC value for vigorous intensity PA is consistent with findings of other studies that found the reliability of vigorous intensity activity to be higher compared to that of moderate intensity activity. ${ }^{10} 303435$ Compared to structured vigorous PAs such as sports and exercise, which can be more easily recalled, moderate intensity $\mathrm{PA}$ is often of low salience, incidental and may not easily be remembered by people. ${ }^{36}{ }^{37}$ Furthermore, our finding that the reliability of vigorous intensity PA was meaningfully higher among men than women seems to confirm our previous findings with the IPAQ-SF. ${ }^{21}$ Plausibly, men in Nigeria are more consistent than women when responding to PA items that pertain to intense vigorous PA than other intensities of activity. Overall, the moderate-to-good evidence of reliability found for all items indicates that the modified IPAQ-LF is reproducible, internally consistent and is promising for research in Nigeria.

Except for sitting time, the limits of agreement in the mean scores of total PA and MVPA between the first and second administrations were wide, suggesting an evidence of bias between administrations. Large differences in PA scores between the two administrations would indicate that at least one of the two measurements is not accurate. However, similar to the finding of a Mexican study, ${ }^{38}$ scores on the Hausa IPAQ-LF were consistently lower during the second administration of the questionnaire compared to the first administration. Since familiarity with the IPAQ questions may improve over multiple exposures to the questionnaire, it is possible that participants in our study might have over-reported their PA levels during the first administration of the Hausa IPAQ-LF. These kind of findings may have implications for the utility of IPAQ for surveillance. Generally, due to issues of social desirability phenomenon and over-reporting of PA that has been associated with the IPAQ ${ }^{39} 40$ it may be necessary to start considering the need for multiple measurements when using the IPAQ for evaluating PA, especially in developing African countries. However, patterns of PA as measured by the modified IPAQ-LF during both administrations were consistently similar, and both administrations were able to discriminate $\mathrm{PA}$ in the expected direction between subgroups of our sample. For example, at both measurement time points, and consistent with hypothesis, men reported more time in active transportation, occupational PA and leisure PA than women, while women reported more time in domestic PA and sedentary activity than men.

In the absence of objective criterion standards for evaluating an absolute estimate of PA, the consistency of 
items on IPAQ with variables known to be related to PA, such as BMI, blood pressure, heart rate, indicators of lipid and glucose metabolism, and fitness index have been used as important construct validity measures. $^{7} 1021{ }^{24}$ In the present study, the correlations of the PA domains and intensities with biological and anthropometric variables were mostly significant in the expected direction, but they were low, suggesting a modest evidence of construct validity for the modified IPAQ-LF in Nigeria. However, observed correlations were comparable with the values in other studies that have evaluated the IPAQ-LF. 7824303339 Since better validity coefficients have been reported for other PA measures above those of the IPAQ ${ }^{39}{ }^{41}$ with the present African finding, it is possible that the IPAQ-LF only has modest evidence of construct validity. However, our findings on the relationships between $\mathrm{PA}$ and biological and anthropometric variables should be interpreted in the light of an important caution. Since hypertensive and obese people may get oriented to exercise, ${ }^{3}$ crosssectional associations of PA and blood pressure or BMI could also occur in the opposite direction and may not represent much information as indicators of construct validity of PA measures.

\section{Strengths and limitations}

A strength of this study is the systematic adaptation and tailoring of items on the IPAQ-LF to reflect the common PA behaviours of people in Nigeria. This is the first study in an African country to explore the cultural adaptation and translation of the IPAQ-LF, and its findings demonstrated the feasibility of using the IPAQ-LF to reliably collect PA data in a diverse segment of the Nigerian population. In the Africa region, the importance of a valid and established PA scale such as the modified IPAQ-LF is not only important to monitoring the domain in which activity is performed, but also very critical to understanding studies of ecological models of health behaviours that emphasise the importance of multiple levels of influence on health behaviours including PA. ${ }^{18}{ }^{42}$ In Nigeria, emerging evidence from studies using ecological models indicate that favourable built environmental attributes are promising for improving total and moderate-to-vigorous $\mathrm{PA}$ and controlling obesity among adults. ${ }^{26} 43-45$ However, built environment characteristics are expected to be strongly related to specific PA types rather than overall PA. ${ }^{46}$ For example, different environmental variables can be related to walking for leisure or transportation and to moderate PA for household, occupation, recreation or transportation. Thus, a study of adaptation of the IPAQ-LF is very important to understanding the domain-specific nature of ecological model research in the African region. One additional strength was the exploration of PA patterns by gender, educational level and employment status, the findings of which were consistent with general hypothesis on social patterns of inactivity in low-income countries. $^{20} 48$
However, the findings of this study should be interpreted in the light of some important limitations. Direct comparison of our validity findings with previous studies should be made with caution, because unlike in our study, the accelerometer or PA diary were utilised as a common objective criterion standard to validate the IPAQ in the majority of the studies. ${ }^{58243033} 39$ Thus, examining the construct validity through the relationships of PA with BMI and resting blood pressure was an important limitation of our study. The choice and availability of appropriate criterion measures are particular issues of concern for the validation of PA questionnaires in low-income countries of Africa. ${ }^{5} 4950$ Despite these issues, the validity coefficients in our study were remarkably similar to those reported in other studies, ${ }^{5} 7824303339$ and the consistency of items on IPAQ with variables known to be related to $\mathrm{PA}$, such as BMI, blood pressure, heart rate, indicators of lipid and glucose metabolism and fitness index have previously been used as important construct validity measures. ${ }^{7102124}$ Another limitation of the study is the use of non-probability sampling technique. The study finding may have limited generalisability to other samples of Nigerians that have different characteristics from this sample. In addition, the majority of participants have more than secondary school education with potentially higher comprehension and recall ability than may be found in the general population. Nevertheless, recruitment from diverse neighbourhoods and settings allowed for a sample with reasonable heterogeneity in age, occupational status and ethnic backgrounds and made it possible to stratify the analyses by sociodemographic characteristics. However, because some of the participants in the present study required assistance to complete the survey, interview administration rather than self-administration of the IPAQ-LF should be encouraged in any future national studies in the African region. Administering the IPAQ through interview has been considered as a viable and preferred option in developing countries. ${ }^{5}$

\section{Conclusions}

Overall, the present study suggests that the modified IPAQ-LF demonstrated sufficient evidence of test-retest reliability and may be valid for assessing context specific PA behaviours of adults in Nigeria. Adaptation and criterion evaluation of the IPAQ-LF in other African countries could further contribute to our understanding of the impact of multiple levels of influence on PA behaviours of people in the African region.

Acknowledgements The authors are grateful to Mrs Salamatu U Aliyu and Mr Sa'adu Inusa Kiriri for their help with questionnaire translations, and to the participants for their help for taking part in the study.

Contributors ALO conceived and designed the study, contributed to cultural adaptation and acquisition of data, conducted the statistical analysis and interpretation of data, and drafted the manuscript. UMB and STP managed participants' recruitment and data collection, and contributed to cultural adaptation. HNA and RWM contributed to cultural adaptation and translations of the measure. AYO contributed to study design, acquisition of data and 
critically revised the manuscript for important intellectual content. All authors read and approved the final manuscript.

Funding This research received no specific grant from any funding agency in the public, commercial or not-for-profit sectors.

Competing interests None.

Ethics approval Research and Ethic Committee of the University of Maiduguri Teaching Hospital, Nigeria (ADM/TH/EC/75).

Provenance and peer review Not commissioned; externally peer reviewed.

Data sharing statement Data set for this study available upon request from the corresponding author.

Open Access This is an Open Access article distributed in accordance with the Creative Commons Attribution Non Commercial (CC BY-NC 4.0) license, which permits others to distribute, remix, adapt, build upon this work noncommercially, and license their derivative works on different terms, provided the original work is properly cited and the use is non-commercial. See: http:// creativecommons.org/licenses/by-nc/4.0/

\section{REFERENCES}

1. Garber CE, Blissmer B, Deschenes MR, et al.; for the American College of Sports Medicine. Quantity and quality of exercise for developing and maintaining cardiorespiratory, musculoskeletal, and neuromotor fitness in apparently healthy adults: guidance for prescribing exercise. Med Sci Sports Exerc 2011;43:1334-59.

2. World Health Organization. Global recommendations on physical activity for health. Geneva, Switzerland: WHO, 2010.

3. Haskell WL, Lee I-M, Pate RP, et al. Physical activity and public health: updated recommendation for adults from the American College of Sports Medicine and the American Heart Association. Circulation 2007;116:1081-93.

4. World Health Assembly 57.17. Global strategy on diet and physical activity. Geneva: World Health Organization, 2004.

5. Craig CL, Marshall AL, Sjostrom M, et al. International physical activity questionnaire: 12 country reliability and validity. Med Sci Sports Exerc 2003;35:1381-95.

6. The IPAQ group. International physical activity questionnaire. 2014. http://www.ipaq.ki.se/scoring.pdf (accessed 21 May 2014).

7. Hagstromer M, Oja P, Sjostrom M. The international physical activity questionnaire (IPAQ) a study of concurrent and construct validity. Public Health Nutr 2006;9:755-62.

8. Hagstromer M, Ainsworth BE, Oja P, et al. Comparison of a subjective and an objective measure of physical activity in a population sample. J Phys Act Health 2010;7:541-50.

9. Maddison R, Mhurchu CN, Jiang $\mathrm{Y}$, et al. International physical activity questionnaire (IPAQ) and New Zealand physical activity questionnaire (NZPAP): A doubly labelled water validation. Int $J$ Behav Nutr Phys Act 2007;4:62.

10. Kurtze N, Rangul V, Hustveldt B. Reliability and validity of the international physical activity questionnaire in the Nord-Trondelag Health Study (HUNT) population of men. BMC Med Res Methodol 2008;8:63.

11. Nicaise V, Marshall S, Ainsworth BE. Domain-specific physical activity and self-report bias among low-income Latinas living in San Diego county. J Phys Act Health 2011;8:881-90.

12. Vandelanotte C, De BourdeaudInij I, Philippaerts R, et al. Reliability and validity of a computerized and Dutch version of the International Physical Activity Questionnaire (IPAQ). J Phys Act Health 2005;2:63-75.

13. Loney T, Standage M, Thompson D, et al. Self-Report vs. objectively assessed physical activity: which is right for public health? J Phys Act Health 2011;8:62-70.

14. Mackay LM, Oliver M, Schofield GM. Demographic variations in discrepancies between objective and subjective measures of physical activity. Open J Prev Med 2011;1:13-19.

15. Kolbe-Alexander TL, Lambert EV, Harkins JB, et al. Comparison of two methods of measuring physical activity in South African older adults. J Aging Phys Act 2006;14:98-114.

16. Pratt $\mathrm{M}$, Sarmiento OL, Montes $\mathrm{F}$, et al. The implications of megatrends in information and communication technology and transportation for changes in global physical activity. Lancet 2012;380:282-93.

17. Kohl III HW, Criag CL, Lambert EV, et al; for the Lancet physical activity series working group. The pandemic of physical inactivity: global action for public health. Lancet 2012;380:294-305.
18. Bauman AE, Reis RS, Sallis JF, et al. Correlates of physical activity: why are some physical active and others not? Lancet 2012;380:258-71.

19. Heath GW, Parra DC, Sarmiento OL, et al. Evidence-based intervention in physical activity: lessons from around the world. Lancet 2012;380:278-81.

20. Hallal PC, Andersen LB, Bull FC, et al.; for the Lancet physical activity series working group. Global physical activity levels: surveillance progress, pitfalls, and prospects. Lancet 2012;380:247-57.

21. Oyeyemi AL, Oyeyemi AY, Adegoke BOA, et al. Cross-cultural adaptation of the international physical activity questionnaire: reliability and validity of the Hausa version in Nigeria. BMC Med Res Methodol 2011;11:156

22. Chu AH, Moy FM. Reliability and validity of the Malay international physical activity questionnaire (IPAQ-M) among a Malay population in Malaysia. Asia Pac J Public Health 2013. Published Online First: 16 May 2012. doi: 1010539512444120.

23. Chun MY. Validity and reliability of Korean version of international physical activity questionnaire short form in the elderly. Korean $J$ Fam Med 2012;33:144-51.

24. Graff-Iversen S, Anderssen SA, Holme IM, et al. An adapted version of the long international physical activity questionnaire (IPAQ L): construct validity in a low income, multiethnic population study from Oslo, Norway. Int J Behav Nutr Phys Act 2007;4:13

25. Lee IM, Shiroma EJ, Lobelo $F$, et al. for the Lancet physical activity series working group effect of physical inactivity on major non-communicable diseases worldwide: an analysis of burden of diseases and life expectancy. Lancet 2012;380:219-29.

26. Oyeyemi AL, Sallis JF, Deforche B, et al. Evaluation of the neighborhood environment walkability scale in Nigeria. Int $J$ Health Geogr 2013;12:16.

27. National Bureau of Statistics. Statistical fact sheet and population census. Federal Republic of Nigeria, 2008. http://www.nigerianstat. gov.ng (accessed 28 Aug 2012).

28. National Population Commission (NPC) [Nigeria] and ORC Macro. Nigeria demographics and health survey 2003. Calverton, Maryland: National Population Commission and ORC Macro, 2004.

29. World Health Organization. Obesity: preventing and managing the global epidemic. WHO Technical Report Series 894. World Health Organization, 2000. http://whqlibdoc.who.int/trs/WHO_TRS_894.pdf (accessed 23 Aug 2013).

30. Vasheghani-Farahani A, Tahmusbi M, Sheri $\mathrm{H}$, et al. The Persian, last 7-day, long form of the International Physical Activity Questionnaire: translation and validation study. Asian J Sports Med 2011;2:106-16.

31. Portney L, White M. Foundations of clinical research. Applications to practice. New Jersey: Pearson Education Inc, 2009.

32. Bland JM, Altman DG. Statistical methods for assessing agreement between two methods of clinical measurement. Lancet 1986;1:307-10.

33. Levy SS, Readdy RT. Reliability of the international physical activity questionnaire in research setting: last 7-day self-administered long form. Meas Phys Educ Exerc Sci 2009;13:191-205.

34. Macfarlane D, Chan A, Cerin E. Examining the validity and reliability of the Chinese version of the International Physical Activity Questionnaire, long form (IPAQ-LC). Public Health Nutr 2010;14:443-50.

35. Papathanasiou G, Georgoudis G, Papandreou M, et al. Reliability measures of the short international physical activity questionnaire (IPAQ) in Greek young adults. Hellenic J Cardiol 2009;50: 283-94.

36. Sallis JF, Saelens BE. Assessment of physical activity by self-report: status, limitations, and future directions. Res $Q$ Exerc Sport 2000;71:1-14

37. Washburn RA, Heath GW, Jackson AW. Reliability and validity issues concerning large-scale surveillance of physical activity. Res Q Exerc Sport 2000;71:104-13.

38. Medina C, Barquera S, Janssen I. Validity and reliability of the International Physical Activity Questionnaire among adults in Mexico. Rev Panam Salud Publica 2013;34:21-8.

39. Johnson-Kozlow M, Sallis JF, Gilpin EA, et al. Comparative validation of the IPAQ and the 7-Day PAR among women diagnosed with breast cancer. Int J Behav Nutr Phys Act 2006;3:7.

40. Rzewnicki R, Vanden Auweele Y, De Bourdeaudhuij I. Addressing over-reporting on the International Physical Activity Questionnaire (IPAQ) telephone survey with a population sample. Public Health Nutr 2003;6:299-305.

41. Aishworth BE, Macera CA, Jones DA, et al. Comparison of the 2001 BRFSS and the IPAQ physical activity questionnaire. Med Sci Sports Exerc 2006;38:1584-92.

42. Sallis JF, Owen N, Fisher EB. Ecological models of health behavior. In: Glanz K, Rimer BK, Viswanath K, eds. Health behavior and 
health education: theory, research, and practice, 4th edn. San Francisco: Jossey-Bass, 2008:465-86.

43. Oyeyemi AL, Adegoke BOA, Oyeyemi AY, et al. Perceived environmental correlates of physical activity and walking in African young adults. Am J Health Promot 2011;25:e10-19.

44. Oyeyemi AL, Adegoke BOA, Oyeyemi AY, et al. Environmental factors associated with overweight among adults in Nigeria. Int $J$ Behav Nutr Phys Act 2012;9:32.

45. Oyeyemi AL, Sallis JF, Adegoke BOA, et al. Perception of neighborhood safety is related with physical activity among adults in Nigeria. BMC Public Health 2012;12:294.

46. Giles-Corti B, Timperio A, Bull F, et al. Understanding physical activity environmental correlates: increased specificity for ecological models. Exerc Sports Sci Rev 2005;33:175-81.
47. Sallis JF, Cervero R, Ascher WW, et al. An ecological approach to creating active living communities. Annu Rev Public Health 2006;27:297-322.

48. Dumith SC, Hallal PC, Reis RS, et al. Worldwide prevalence of physical and its association with human development index in 76 countries. Prev Med 2011;50:24-8.

49. Oyeyemi AL, Umar M, Ugoche F, et al. Accelerometer-determined physical activity and its comparison with the International Physical Activity Questionnaire in a sample of Nigerian adults. PLOS ONE 2014;9:e872333.

50. Sobnqwi E, Mbanya JCN, Urwin NC, et al. Development and validation of a questionnaire for the assessment of physical activity in epidemiological studies in Sub-Saharan Africa. Int J Epidemiol 2001;30:1361-8. 